\title{
Game Edukasi Aksara Jawa Menggunakan Augmented Reality Berbasis Android
}

\author{
Heru Kurniawan Ramadani ${ }^{1}$, Walidini Syaihul Huda ${ }^{2}$ \\ ${ }^{1,2)}$ Program Studi Teknik Informatika, Universitas Yudharta, Pasuruan, Indonesia \\ email: ${ }^{1}$ herukurniawan43@gmail.com, ${ }^{2}$ walidini.uyp@gmail.com
}

\begin{tabular}{l}
\hline INFO ARTIKEL \\
\hline Sejarah Artikel: \\
Diterima 6 Mei 2020 \\
Direvisi 16 Desember 2020 \\
Disetujui 19 Desember 2020 \\
Dipublikasi 22 Desember 2020 \\
\hline Katakunci: \\
Augmented Reality \\
Aksara Jawa \\
Waterfall \\
Game Edukasi
\end{tabular}

\begin{abstract}
ABSTRAK
Aksara Jawa menjadi bagian dari peninggalan kebudayaan Jawa yang tidak ternilai harganya, tak akan lekang oleh waktu, dan patut untuk dilestarikan. Aksara ini lebih dikenal sebagai Hanacaraka. Banyak masyarakat yang kesulitan mempelajari Aksara Jawa ini, dikarenakan bentuknya maupun cara penulisannya yang berbeda dengan Aksara Latin, Aksara Arab, atau yang lainnya. Penelitian ini menggunakan metode Waterfall. Tahapan dari metode waterfall ini adalah analisa kebutuhan sistem, desain sistem, penulisan kode program (coding), pengujian program (testing), penerapan program dan pemeliharaan (maintenance). Ada banyak cara mengenalkan Aksara Jawa ke masyarakat terutama ke anak-anak, diantaranya bisa dengan melalui teknologi Augmented Reality. Teknologi AR ini merepresentasikan objek nyata (real) menjadi objek yang maya berupa gambar 3D, video ataupun audio. Teknologi ini digunakan untuk mengenalkan Aksara Jawa dalam bentuk game edukasi, agar Aksara Jawa lebih dilestarikan dan dipahami terutama generasi milenial saat ini. Pengembangan ini diharapkan agar menjadi alternatif lain sarana belajar anak-anak, maupun sarana pembelajaran bagi orang tua maupun pendidik di sekolah selain dari media buku. Hasil dari penelitian ini menunjukkan bahwa adanya ketertarikan responden untuk belajar aksara jawa sebesar $60 \%$ menggunakan teknologi augmented reality (AR) pada game android dibandingkan menggunakan media buku.
\end{abstract}

Keyword:
Augmented Reality
Javanese Script
Waterfall

Educational Games

DOI Artikel:

10.35891/explorit.v12i2.2281

\section{ABSTRACT}

Javanese script is part of the Javanese cultural heritage that is priceless, timeless, and deserves to be preserved. This script is better known as Hanacaraka. Many people have difficulty learning this Javanese script, because of its shape and the way it is written which is different from Latin script, Arabic script, or others. This study uses the Waterfall method. The stages of this waterfall method are system requirements analysis, system design, coding, program testing, program implementation and maintenance. There are many ways to introduce Javanese script to the community, especially to children, including through Augmented Reality technology. This AR technology represents real objects (real) into virtual objects in the form of 3D images, video or audio. This technology is used to introduce Javanese script in the form of educational games, so that Javanese script is more preserved and understood, especially the current millennial generation. This development is expected to be another alternative means of learning for children, as well as a means of learning for parents and educators in schools apart from books. The results of this study indicate that $60 \%$ of respondents are interested in learning Javanese script using augmented reality (AR) technology in android games compared to using book media.

@ 2020 diterbitkan oleh Prodi Teknik Informatika Universitas Yudharta Pasuruan

\section{Pendahuluan}

Aksara Jawa merupakan aset karakter tertentu yang digunakan oleh pulau Jawa dan karakter ini masih sering ditemukan di papan nama jalan, dinding mengidam atau peninggalan sejarah lainnya. Aksara Jawa juga dianggap sebagai warisan nasional Indonesia.[1] Aksara Jawa menjadi bagian dari peninggalan kebudayaan Jawa yang tidak ternilai harganya, tak akan lekang oleh waktu, dan patut untuk dilestarikan. Aksara ini dikenal masyarakat sebagai aksara Hanacaraka.

Semakin berkembangnya teknologi seperti sekarang ini, Aksara Jawa seakan ikut hilang dilupakan. Keterampilan siswa untuk membaca huruf aksara jawa masih rendah. Ini dikarenakan masih kesulitan dalam memahami bentuk hurufnya yang beraneka ragam. Hal ini menjadikan aksara jawa salah satu yang kurang diminati generasi muda terutama dalam mempelajari mata pelajaran bahasa Jawa.[2]

Berdasarkan survey yang dilakukan terhadap 35 responden dengan rentang usia 13-15 tahun atau di tingkat SMP mendapati bahwa 91,4\% mereka masih menggunakan buku pepak atau media konvensional seperti buku paket. Namun apabila buku pepak atau media konvensional digantikan dengan memakai game Android, menyimpulkan bahwa 60\% lebih tertarik menggunakan Android sebagai media belajar dibandingkan dengan buku.

Pada penelitian terdahulu sudah membuat aplikasi edukasi Aksara Jawa menggunakan Augmented Reality sebagai media pembelajaran, Diantara penelitian tersebut yaitu aplikasi tracking marker (mengarahkan kamera ke marker yang sudah dicetak) dengan memakai metode Waterfall sebagai metode pembuatannya [3]. Pada penelitian lain juga dilakukan dengan memakai metode Appreciative Learning dalam menampilkan objek 3D menggunakan marker yang dicetak menjadi bentuk buku [2].

Kekurangan dari 2 penelitian terdahulu tentang pembuatan aplikasi edukasi Aksara Jawa ini adalah masih fokus terhadap scan marker saja, lalu belum adanya tombol untuk mengeluarkan suara yang menunjukkan Aksara apa yang sedang ditampilkan. Kelebihan dari 2 penelitian terdahulu 
tersebut adalah mampu meningkatkan minat belajar anak-anak di usia SMP dengan tampilan user interface yang sederhana namun mudah dipahami.

Berbeda halnya dengan beberapa penelitian yang sebelumnya, dalam penelitian ini akan dilakukan penambahan fitur untuk menampilkan suara pada saat objek 3D tampil saat kamera mengarah ke marker. Dengan ditambahkan suara ini, diharapkan pengguna di rentang usia SMP dapat mengetahui bagaimana cara baca Aksara yang sedang ditampilkan di layar. Dalam penelitian ini, penulis menggunakan metode Waterfall sebagai acuan dalam merancang sistem dalam pengembangan aplikasi game edukasi Aksara Jawa ini.

\section{Tinjauan Pustaka}

a. Penelitian Terkait.

Dalam mendukung sebuah penelitian, penulis perlu mengacu pada penelitian terdahulu yang memiliki keterkaitan yang relevan baik secara langsung maupun tidak langsung, secara metode maupun secara teori, terhadap penelitian yang akan dilakukan. Beberapa penelitian terkait diantaranya sebagai berikut:

1. Penerapan Teknologi Augmented Reality Berbasis Android Sebagai Media Pembelajaran Pengenalan Aksara Jawa Di SDN 1 Sidorejo Ponorogo

Bahwa siswa masih cukup banyak kurang terampil dalam menulis huruf jawa. Maka dibutuhkan media pembelajaran baru sebagai sarana yang digunakan untuk kegiatan belajar mengajar supaya lebih menarik. Metode pembuatan aplikasi ini menggunakan model Waterfall, dimana prosesnya dimulai dari analisis kebutuhan, Design, Coding, Testing, dan maintenance. Tujuan dari penelitian yang dilakukan ini adalah membuat dan mengenalkan aplikasi Augmented Reality sebagai media pembelajaran untuk mengenalkan aksara jawa menggunakan android agar nanti dapat dipakai sebagai media pembelajaran yang interaktif dan menarik bagi siswa. Hasil yang didapat dari metode ini adalah terbantunya pengguna dalam memahami bentuk Aksara Jawa, dan membantu guru dalam memanfaatkan teknologi IT.[3]

2. Aplikasi Edukasi Aksara Jawa Sebagai Media Pembelajaran Berbasis Android

Penelitian ini dirancang dengan menggunakan metode System Development Life Cycle (SDLC) dengan jenis Waterfall Diagram. Hasil dari penelitian ini adalah aplikasi bernama ANJAWA dengan beberapa fitur, diantaranya adalah pembelajaran aksara jawa dari aksara carakan, pasangan, sandhangan, wilangan dan aksara swara, kemudian bisa mengeluarkan suara dari setiap aksara carakan, lalu soal yang dapat dengan mudah membantu menghafal setiap huruf Aksara Jawa.[4]

b. Landasan Teori

1. Aksara Jawa

Aksara jawa adalah satu dari sekian banyak bahasa lisan yang didapat dari pengaruh kebudayaan Hindu-Budha serta dari Kebudayaan Islam. Aksara Jawa sendiri merupakan aksara yang dipakai untuk menulis bahasa Jawa, yaitu bahasa asli dari salah satu kelompok masyarakat yang menghuni pulau Jawa. Aksara Jawa turunan dari aksara Brahmi kuno dari wilayah India, sehingga aksara Jawa secara tidak langsung memiliki banyak kesamaan dengan aksara-aksara di wilayah Asia Selatan dan juga Asia Tenggara. Aksara Jawa juga dipakai untuk menulis Bahasa Sanskerta, Jawa kuno, aksara kawi, serta juga dipakai untuk menulis bahasa Sunda dan Sasak.[5]

2. Android

Android merupakan mobile operating system atau sistem operasi bergerak yang diadopsi dari Linux[6], tapi telah dimodifikasi. Pada tahun 2005 silam, Android telah diambil alih oleh Google dengan mengambil alih seluruh perusahaan, termasuk juga tim yang mengembangkan Android. Keuntungan utama dari Android adalah pengembang (developer)hanya berkonsentrasi pada aplikasi saja. Aplikasi tersebut bisa digunakan di perangkat yang berbeda-beda selama masih menggunakan sistem operasi Android.[7]

3. Augmented Reality

Augmented Reality (AR) adalah jembatan atau penghubung antara dunia nyata (real) dengan dunia maya (virtual) secara realtime (Sagita \& Amalia, 2014). Haller, Billinghurst \& Thomas (2007:7) mengatakan bahwa riset Augmented Reality memiliki tujuan mengembangkan sebuah teknologi yang memungkinkan penggabungan secara real-time terhadap digital content yang dibuat oleh komputer dengan dunia nyata. Augmented Reality memungkinkan user melihat benda maya (virtual) 2D (dua dimensi) atau 3D (tiga dimensi) yang divisualisasikan terhadap dunia nyata (real).[8]

4. Vuforia SDK

Vuforia merupakan Software Development Kit (SDK) yang dikembangkan Qualcomm untuk digunakan pengembang (developer) dalam membuat aplikasi atau game berbasis Augmented Reality (AR). Vuforia SDK memudahkan dan mempercepat seorang pengembang untuk membuat aplikasi berteknologi Augmented Reality. Pengembang cukup tinggal berimajinasi saja dan mengembangkan aplikasi yang menarik menggunakan SDK ini karena library dan fungsi-fungsi intinya telah dibuat oleh Qualcomm.[9]

5. Unity

Unity merupakan game engine yang membuat pengembangan game lebih mudah dilakukan bagi pengguna yang awam sehingga mereka dapat membuat game mereka sendiri. Unity dapat menyatukan semuanya dengan antarmuka yang lengkap dan fungsi crossplatform yang dapat menghemat waktu ribuan jam bagi pengembang daripada harus membuat game tersebut dari awal dan bahkan harus membuat versi yang berbeda untuk setiap platform yang ada, seperti Windows, Android, dan iOS.[10]

6. Blender

Blender merupakan satu dari banyak software open source yang dipakai pengembang untuk membuat aplikasi multimedia khususnya 3 Dimensi. Blender mempunyai beberapa kelebihan, diantaranya yaitu :

1. Open Source

Blender adalah satu diantara banyak software open source, dimana bisa dengan bebas merubah source codenya untuk keperluan pribadi maupun komersial asalkan tidak sampai melanggar GNU (General Public License).

2. Multi-Platform

Blender tersedia untuk berbagai macam sistem operasi seperti Linux, Mac, dan Windows karena sifatnya yang open source.

3. Update

Software ini lebih cepat dalam hal update dibandingkan software yang lainnya, karena bisa dikembangkan oleh siapapun.

4. Free 
Blender adalah sebuah software tidak berbayar yang bisa dipakai oleh siapapun.

5. Lengkap

Dibandingkan software 3D lainnya, Blender mempunyai fitur yang lebih lengkap.

6. Ringan

Untuk menjalankan Blender, dibutuhkan spesifikasi sistem yang rendah. Hal ini yang membuat Blender menjadi software 3D yang lebih ringan dari lainnya.

c. Kerangka Pemikiran

Kerangka pemikiran dalam penelitian ini diilustrasikan seperti berikut ini.

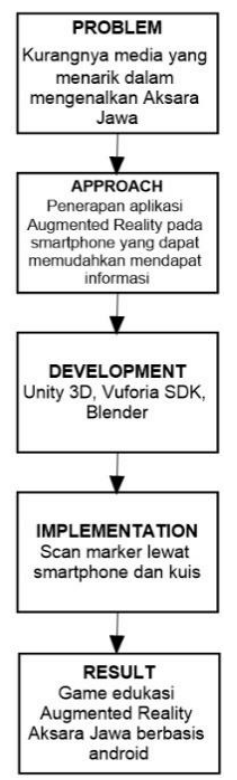

Gambar 1. Kerangka Pemikiran

\section{Metodologi Penelitian}

Dalam mengembangkan aplikasi game edukasi ini, metode yang digunakan adalah metode waterfall. Alasan menggunakan metode ini dikarenakan metode ini melakukan pendekatan yang sistematis dan berurutan dalam membangun atau mengembangkan perangkat lunak. Metode ini banyak digunakan oleh pengembang perangkat lunak dengan hasil sistem yang berkualitas, dikarenakan pelaksanaannya secara bertahap sehingga tidak fokus pada tahapan tertentu.

Tahapan dari metode waterfall ini adalah analisa kebutuhan sistem, desain sistem, penulisan kode program (coding), pengujian program (testing), penerapan program dan pemeliharaan (maintenance).

a. Analisa Kebutuhan

Kebutuhan ini meliputi kebutuhan perangkat lunak (software) dan perangkat keras (hardware). Perlunya analisa ini supaya pengembang bisa melakukan tugasnya dengan lancar dan minim dengan risiko.

Tabel 1. Kebutuhan Perangkat Lunak

\begin{tabular}{|c|l|l|}
\hline No & \multicolumn{1}{|c|}{ Perangkat Lunak } & \multicolumn{1}{c|}{ Versi } \\
\hline 1 & OS Windows 10 x64 & $1903($ OS Build 18362) \\
\hline 2 & Unity & $2018.2 .0 \mathrm{~b} 1$ \\
\hline 3 & Blender & 2.78 \\
\hline 4 & Vuforia SDK & 8.3 .8 \\
\hline
\end{tabular}

Tabel 2. Kebutuhan Perangkat Keras
\begin{tabular}{|c|l|l|}
\hline No & Perangkat Keras & \multicolumn{1}{c|}{ Spesifikasi } \\
\hline 1 & Merk \& Tipe Laptop & Lenovo Ideapad 320 \\
\hline 2 & Processor & AMD A $9-94203.0 \mathrm{GHz}$ \\
\hline 3 & Grafik & AMD Radeon R $1 \mathrm{~GB}$ \\
\hline 4 & RAM & 8 GB DDR4 \\
\hline 5 & Hardisk & 120 GB SSD, 1 TB HDD \\
\hline
\end{tabular}

b. Desain Sistem

Tahap ini mempunyai tujuan memberikan gambaran apa saja yang akan dilakukan dan bagaimana tampilan programnya. Dalam tahapan desain sistem berikut ini menghasilkan beberapa rancangan antara lain, Use Case Diagram, Flowchart, dan perancangan desain interface. 


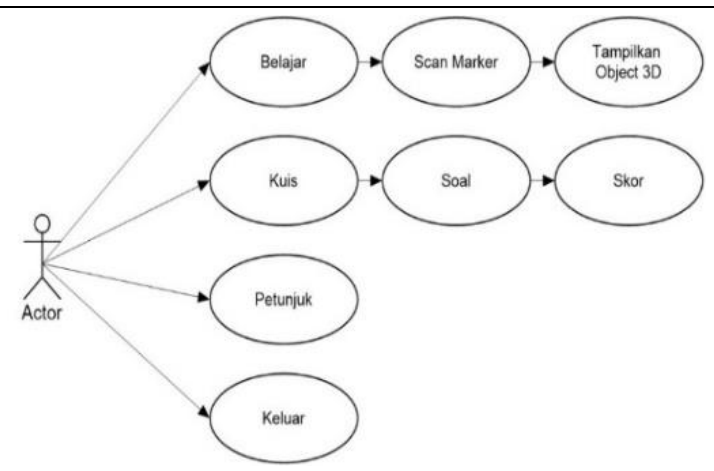

Gambar 2. Use Case Diagram

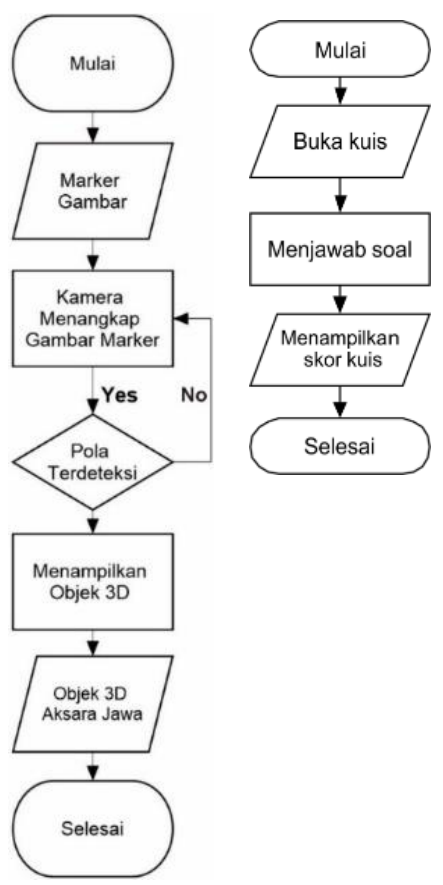

Gambar 3. Flowchart Desain Sistem Scan Marker dan Kuis

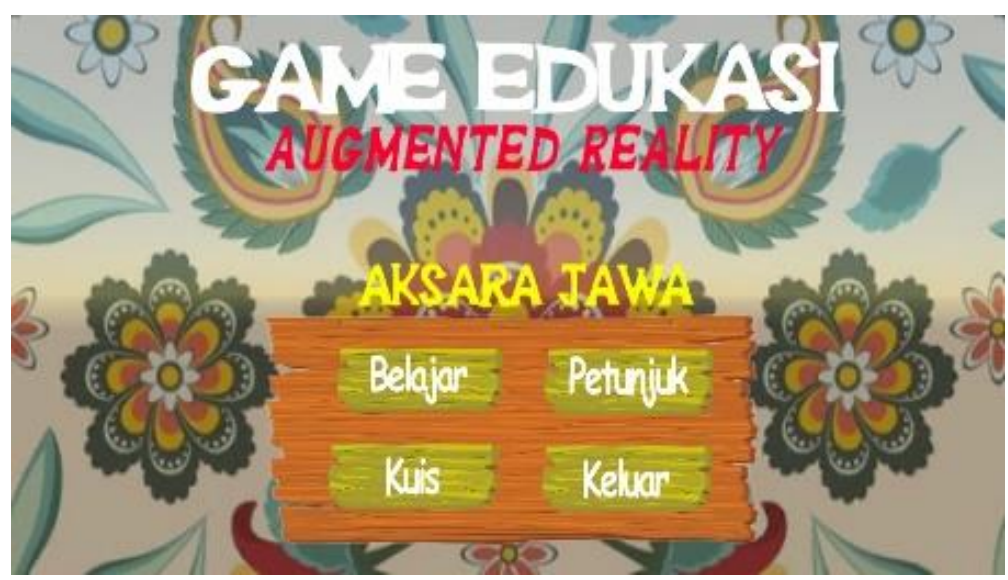

Gambar 4. Desain Interface Halaman Awal

c. Penulisan Kode Program (Coding)

Penulisan coding ini merupakan tahap menuliskan perintah - perintah dalam Bahasa pemrograman yang dimengerti komputer. Tahap ini adalah tahapan yang sangat utama dalam membangun sebuah sistem.

d. Pengujian Program (Testing)

Tahap ini bertujuan untuk memastikan jika software yang telah dibuat semua fungsinya bisa digunakan dengan baik dan sesuai dengan desain tanpa adanya kesalahan (bug). Pengujian program ini menggunakan metode blackbox untuk pengecekan aplikasi yang dibangun, apakah aplikasi ada errornya atau tidak.

e. Penerapan Program dan Pemeliharaan (Maintenance).

Pemeliharaan ini adalah memperbaiki error yang tidak ditemukan pada tahap-tahap sebelumnya, pengembangan sistem, penambahan fitur, serta peningkatan performa. 


\section{Hasil Uji Coba Dan Pembahasan}

1. Pengujian Aplikasi

Pengujian aplikasi ini menggunakan metode pengujian blackbox. Metode ini digunakan untuk menguji fungsi dan fitur dari aplikasi apakah bisa dioperasikan dengan baik dan benar tanpa adanya kesalahan (bug), serta bisa dipakai sesuai dengan yang diharapkan.

Tabel 3. Hasil Pengujian Aplkasi

\begin{tabular}{|c|c|c|c|c|}
\hline No & Pengujian & Hasil yang diharapkan & Hasil pengujian & Kesimpulan \\
\hline 1 & $\begin{array}{l}\text { Install APK } \\
\text { (Minimum Android } 5.0 \\
\text { Lollipop API 22) }\end{array}$ & $\begin{array}{l}\text { Proses instalasi terpasang di } \\
\text { gawai android dengan baik }\end{array}$ & Sesuai harapan & Valid \\
\hline 2 & $\begin{array}{l}\text { Menjalankan aplikasi yang } \\
\text { telah terpasang }\end{array}$ & $\begin{array}{l}\text { Aplikasi dapat dibuka dengan } \\
\text { baik }\end{array}$ & Sesuai harapan & Valid \\
\hline 3 & $\begin{array}{l}\text { Menjalankan kamera sesuai } \\
\text { dengan menu }\end{array}$ & $\begin{array}{l}\text { Bisa mendeteksi marker dan } \\
\text { keluar objek aksara jawa } \\
\text { sesuai menu yang dipilih }\end{array}$ & Sesuai harapan & Valid \\
\hline 4 & $\begin{array}{l}\text { Mendeteksi marker yang } \\
\text { berbeda }\end{array}$ & $\begin{array}{l}\text { Tidak dapat menampilkan } \\
\text { objek aksara }\end{array}$ & Sesuai harapan & Valid \\
\hline 5 & Tombol speaker & $\begin{array}{l}\text { Mengeluarkan suara sesuai } \\
\text { aksara yang discan }\end{array}$ & Sesuai harapan & Valid \\
\hline 6 & Nilai skor & $\begin{array}{l}\text { Menampilkan nilai sesuai } \\
\text { jumlah jawaban yang benar }\end{array}$ & Sesuai harapan & Valid \\
\hline 7 & Tombol Keluar & Keluar aplikasi & Sesuai harapan & Valid \\
\hline
\end{tabular}

2. Pengujian Terhadap Spesifikasi Smartphone

Berikut ini adalah daftar smartphone yang telah diinstall aplikasi game edukasi aksara jawa yang digunakan untuk menguji aplikasi.

Tabel 4. Perangkat Penguji Aplikasi

Tabel 4. Perangkat Penguji Aplikasi
\begin{tabular}{|l|l|l|}
\hline \multicolumn{1}{|c|}{ Perangkat 1 } & \multicolumn{1}{|c|}{ Perangkat 2 } & \multicolumn{1}{|c|}{ Perangkat 3} \\
\hline Xiaomi Redmi 5A & Xiaomi Redmi Note 7 & Samsung J2 Prime \\
Spesifikasi : & Spesifikasi : & Spesifikasi : \\
Processor Quad Core 1.4 & Processor Octa Core 4x2.2 & Processor Quad Core \\
GHz Cortex-A53 & GHz & 1.4 GHz Cortex-A53 \\
Chipset Qualcomm & Chipset Qualcomm & Chipset Mediatek \\
MSM8917 Snapdragon & SDM660 Snapdragon 660 & MT6737T (28nm) \\
425 (28 nm) & RAm) & RAM 1,5GB \\
RAM 2GB & RAM 4GB & Kamera 8 MP \\
Kamera 13 MP & Kamera 48 MP & GPU Mali-T720MP2 \\
GPU Adreno 308 & GPU Adreno 512 & Resolusi 540x960 \\
Resolusi 720x1280 pixel & Resolusi 1080x2340 pixel & pixel 5.0 inch \\
5.0 inch & 6.3 inch & Android 6.0 \\
Android 8.1 Oreo & Android 9.0 Pie & Marshmallow \\
\hline
\end{tabular}

Hasil dari pengujian 3 perangkat smartphone diatas didapatkan beberapa kesimpulan yaitu :

1. Semakin tinggi spesifikasi smartphone, maka memperngaruhi proses pendeteksian pada kamera dalam aplikasi.

2. Resolusi layar smartphone mempengaruhi tampilan aplikasi. Pada perangkat penguji aplikasi, tampilan yang paling efektif adalah di layar ukuran 720x1280 pixel.

3. Untuk di ukuran layar 1080x2340 pixel, didapati tampilan aplikasi sedikit lebih kecil, lalu di layar 540x960 pixel, tampilan aplikasi sedikit lebih besar.

\section{Kesimpulan dan Saran}

a. Kesimpulan

Berdasarkan penelitian yang sudah dilakukan oleh penulis, maka dapat menyimpulkan bahwa:

1. Hasil dari pengujian fungsi dan pengujian jarak pada aplikasi bisa berjalan dengan baik.

2. Hasil dari pengujian sampel menggunakan metode T-Test menyimpulkan bahwa hipotesis alternatif diterima. Yang artinya responden lebih tertarik untuk belajar aksara jawa melalui game android dibandingkan dengan menggunakan buku.

3. Proses pendeteksian marker terhadap kamera di smartphone sangat berpengaruh dari faktor ukuran pixel, jarak dan sudut kemiringan kamera

b. Saran

Berdasarkan pengujian terhadap aplikasi yang telah dibuat, dapat penulis berikan saran sebagai berikut:

1. Penelitian ini bisa dikembangkan lagi oleh peneliti berikutnya supaya lebih menarik dan interaktif

2. Pada penelitian berikutnya, penulis memberikan saran agar aplikasi mempunyai konten menu dan objek yang lebih lengkap.

\section{Daftar Pustaka}

[1] G. Abdul Robby, A. Tandra, I. Susanto, J. Harefa, and A. Chowanda, "Implementation of optical character recognition using tes seract with the javanese script target in android application," Procedia Comput. Sci., vol. 157, pp. 499-505, 2019, doi: 10.1016/j.procs.2019.09.006.

[2] N. Ageng Setiyanto, L. Sandjaya, and H. Haryanto, "Model Antarmuka Augmented Reality Interaktif Menggunakan Appreciative Learning Dalam Aplikasi Pembelajaran Aksara Jawa," Techno.com, vol. 15, no. 1, pp. 77-83, 2016.

[3] F. E. E. Kusuma, M. B. Setyawan, and I. A. Zulkarnain, "Penerapan Teknologi Augmented Reality Berbasis Android Sebagai Media Pembelajaran Pengenalan Aksara Jawa Di Sdn 1 Sidorejo Ponorogo," Komputek, vol. 3, no. 1, pp. 61-66, 2019, doi: 10.24269/jkt.v3i1.203.

[4] A. Purnomo, “APLIKASI EDUKASI AKSARA JAWA SEBAGAI MEDIA PEMBELAJARAN BERBASIS ANDROID," Universitas Nusantara PGRI Kediri, 2018.

[5] D. R. Ardiyani, "Keterampilan Membaca Aksara Jawa Melalui Model Quantum Learning Dengan Media Kartu Kata Siswa Kelas Iiia Sdn Petompon 
02 Semarang," UNIVERSITAS NEGERI SEMARANG, 2013.

[6] avysa nabila and M. I. Rosadi, “APLIKASI PENGENALAN DINOSAURUS DENGAN ANIMASI 3D BERBASIS ANDROID MENGGUNAKAN AUGMENTED REALITY (AR)," Explor. IT! J. Keilmuan dan Apl. Tek. Inform., vol. 11, no. 2 SE-Articles, Dec. 2019, doi: 10.35891/explorit.v11i2.1656.

[7] A. Irawan et al., "PERANCANGAN DAN PEMBUATAN TEKNOLOGI AUGMENTED REALITY SEBAGAI MEDIA PEMBELAJARAN AKSARA MINANG DI SDN 01," Maj. Ilm. UPI YPTK, vol. 26, no. 26, pp. 12-21, 2019.

[8] A. W. Saputra, A. Susano, and P. Astuti, "Rancang Bangun Aplikasi Edukasi Hardware Komputer Berbasis Teknologi Augmented Reality dengan Menggunakan Android," Fakt. Exacta, vol. 11, no. 4, p. 310, 2018, doi: 10.30998/faktorexacta.v11i4.3100.

[9] A. W. Putra, "Vuforia - SDK Canggih Untuk Wujudkan Aplikasi dan Game Dengan Teknologi Augmented Reality," 2015. [Online]. Available: https://teknojurnal.com/vuforia/.

[10] A. Sinicki, Unity Untuk Pengembangan Game Android. Yogyakarta: Penerbit ANDI, 2019. 